\title{
La herencia aristotélica \\ en la teoría hegeliana de la sensación como «encontrar-se» vital del espíritu
}

\section{The Aristotelian legacy in the Hegelian theory of perception as a vital self-awareness of spirit}

\author{
JUAN J. PADIAL \\ Universidad de Málaga
}

Recibido: 12/02/2017 Aceptado: 5/5/2017

RESUMEN

Estudio en este texto la recepción que hace Hegel en su Antropología de la teoría aristotélica de la sensación, y de la conciencia sensible. Al establecer la relación entre las dos teorías, se detectan las similitudes y diferencias entre el tratamiento de la sensación en los dos autores.

PALABRAS CLAVE

ARISTÓTELES; HEGEL; PERCEPCIÓN; AUTOCONCIENCIA; CONCIENCIA VITAL; ACTIO IN PASSIO;

\section{ABSTRACT}

I study in this text the reception that Hegel makes in his philosophy of the subjective spirit of the Aristotelian theory of sensation, and of sensible awareness. After establishing the relationship between the two theories, one can detect both the similarities and the differences between the treatment of perception in the two authors.

KEY WORDS:

ARISTOTLE; HEGEL; PERCEPTION; SELFAWARENESS; VITAL CONSCIOUSNESS; ACTIVITY IN RECEPTION;

(C) Contrastes. Revista Internacional de Filosofia, vol. XXII-N² (2017), pp. 75-91. ISSN: 1136-4076

Departamento de Filosofía, Universidad de Málaga, Facultad de Filosofía y Letras Campus de Teatinos, E-29071 Málaga (España) 


\section{LA DEUDA DE LA FILOSOFÍA DEL ESPÍRITU SUBJETIVo CON ARISTÓTELES}

L'eredità greca, éste es el título de un importante artículo de Franco Chiereghin. ${ }^{1} \mathrm{Y}$ este es también el objeto de este volumen. En lo que toca al texto que presento, el objeto es más modesto: la herencia aristotélica en la teoría hegeliana de la sensación y la autoconciencia. No obstante, el intento puede parecer atrevido, pues no pocos han sido los que como Rorty han negado que Aristóteles pueda encontrarse noción alguna de conciencia y mucho menos de autoconciencia. ${ }^{2}$

En el $\S 378$ de la Enciclopedia, Hegel, que se dispone a comenzar la Antropología de su Filosofía del espíritu subjetivo, realiza un encendido elogio a Aristóteles. Allí exclama que

los libros de Aristóteles sobre el alma, con sus tratados sobre distintos aspectos y estados de ella, siguen siendo todavía, por esta causa, la obra más excelente o única con interés especulativo sobre este objeto. ${ }^{3}$

Sorprende que Hegel retroceda veintitrés siglos para encontrar un texto relevante filosóficamente acerca del espíritu subjetivo, es decir y en términos muy generales, sobre antropología y psicología. ${ }^{4} \mathrm{~A}$ este respecto hay preguntas muy interesantes. Por ejemplo, las que propone Ferrarin: «¿cómo es de profunda la deuda hegeliana con Aristóteles en su teoría del espíritu? O, dicho de otro modo, ¿en qué y por qué encuentra Hegel inspiración en Aristóteles? ¿O es que quizás Hegel reconoció simplemente una afinidad [para con el filósofo griego] de tesis que él había ya establecido de modo independiente?». ${ }^{5}$ Estas preguntas son especialmente importantes para comprender algunos aspectos poco estudiados de la filosofía del espíritu subjetivo, y que recientemente han cobrado una inusitada importancia.

Para Hegel, escribir un tratado filosófico y especulativo sobre el espíritu subjetivo era un asunto de suma gravedad. La misma con que veía que había que reformular la Lógica y escribir una Ciencia de la lógica. Su interés era muy sincero y arrancaba de una constatación: veía que estas dos ciencias - la lógica y la filosofía del espíritu subjetivo-, no habían alcanzado la madurez que el

1 Chierighin, F., "L'eredità greca nell'antropologia hegeliana» en Verifiche: rivista trimestrale di scienze umane, ISSN 0391-4186, Vol. 18, No 3, 1989, págs. 239-282.

2 Cfr.: Rorty, R., Philosophy and the Mirror of Nature, Princenton University Press, Princenton NJ., 1980, pp. 34 y ss.

3 Hegel, Enz., § 378.

4 Esa es la denominación con que Hegel solía anunciar sus lecciones sobre filosofía del espíritu subjetivo en la Universidad de Berlín.

5 Ferrarín, A., Hegel and Aristotle, Harvard University Press, Harvard MA, 2004, p. 246. 
momento histórico del saber les exigía. ${ }^{6}$ Las dos quedaron casi en el estado en que Aristóteles las dejó, como si el principio moderno de la subjetividad y la libertad no tuviese eco en ellas. Esto no había pasado en otras ciencias filosóficas: tras el giro copernicano que imprimió Kant a la metafísica, ésta se había beneficiado en mucho; y esa orientación había sido proseguida por los hipercríticos y los idealistas. La Teoría del Conocimiento era la ciencia filosófica más afín a la sensibilidad moderna, e incluso la Filosofía de la Naturaleza, estaba siendo reelaborada de modo muy interesante por románticos y schellinguianos.

Pero no sucedía lo mismo al tratar del espíritu. Por eso, en el $\S 444$ de la Enciclopedia nos dirá que

La psicología se cuenta, como la lógica, entre aquellas ciencias que en los tiempos modernos menos se han beneficiado de la formación general del espíritu y del profundo concepto de la razón, y se encuentra todavía en un estado muy lamentable. ${ }^{7}$

Hegel encuentra la elaboración filosófica de la antropología y la psicología de su tiempo en un estado lamentable. Descubrimientos empíricos los había en las dos ciencias, pero no su elaboración especulativa y sistemática en una ciencia filosófica. El peligro estribaba en la renuncia al conocimiento filosófico del ser humano, a lo que hoy llamaríamos una antropología filosófica. O lo que es lo mismo, a que el único conocimiento válido sobre la subjetividad fuese empírico, y no se alcanzase la cota espiritual. Éste parecía ser el estado de la cuestión dejado por Kant:

En virtud del giro de la filosofía kantiana se le ha concedido desde luego [a la psicología empírica] una mayor importancia, pero eso de tal manera que, en su estado empírico, como ciencia que no consiste en otra cosa que en recoger empíricamente y analizar los hechos de la conciencia humana y precisamente como hechos tal como son dados, debe constituir precisamente la base de la metafísica. ${ }^{8}$

Schulze y Fries se sentían kantianos al realizar un estudio empírico de los hechos de conciencia como peldaño previo que de algún modo complementase a la metafísica o a la lógica, es decir al edificio crítico. Ellos querían elaborar una antropología psíquica, una ciencia empírica de cualquier experiencia posible.

Pero éste no era el espíritu kantiano, que exigía distinguir entre la psicología empírica y la psicología racional crítica. «Para [Kant], aunque el ego de la apercepción pura es un asunto de realidad nouménica, más allá de la

6 Sobre la reformulación de la lógica, véase la carta a Niethammer de octubre de 1811 (cfr.: Briefe, I, 389. Sobre el proyecto de una obra sobre antropología y psicología, véase el $\S 4$ de la Filosofía del Derecho.

7 Enz. § $444 \mathrm{~N}$.

8 Ibidem. 
experiencia, es la base absoluta de la psicología racional crítica — una ciencia a priori y no empírica ( $\mathrm{KrV}$ B 401), que a su vez es la base absoluta de toda la filosofía crítica». ${ }^{9}$ Por ello Kant se muestra un poco ambivalente. Por una parte es consciente de la importancia que tienen las reflexiones empíricas sobre el psiquismo humano. Incluso llega a admitir su vecindad con las cuestiones metafísicas, especulativas diríamos. Pero es preciso distinguir entre la psicología empírica y la psicología crítica a priori. Por eso el lugar de la psicología empírica en la arquitectónica del saber filosófico es provisional y tan sólo exigido por la costumbre universitaria:

De acuerdo con el uso académico, tendremos que permitirle ocupar un pequeño rincón (aunque sólo como episodio) en la metafísica, y ello por razones económicas, ya que su desarrollo no es aún tan rico como para constituir una disciplina por sí sola, mientras que, por otra parte, es demasiado importante como para eliminarla o para encuadrarla en otro lugar donde pudiera encontrar menos afinidad todavía que en la metafísica. No se trata, por tanto, más que de un extraño que acogemos y al que permitimos quedarse por algún tiempo, hasta que pueda instalar su propia residencia en una antropología completa (que forma pareja con la doctrina empírica de la naturaleza). ${ }^{10}$

Hegel también distinguirá entre saberes empíricos acerca del hombre y la filosofía del espíritu subjetivo. Pero el proceder de Hegel será inverso al de Kant. Para éste, la psicología racional crítica es la base de la metafísica. Una base absoluta, desligada de cualquier otro saber. Además, la psicología crítica es un saber a priori.

En cambio, para Hegel la filosofía del espíritu subjetivo es una ciencia que podría calificarse como una reflexión sobre lo psico-biológico. Pero en modo alguno es una elaboración a priori, sino que es una ciencia que intenta ver el espíritu en sus manifestaciones psico-biológicas. La filosofía del espíritu subjetivo, pues es la ciencia que estudia el aparecer natural del espíritu. Además, la psicología tiene como presupuesto la fenomenología del espíritu, que a su vez tiene como presuposición a la antropología, que se apoya sobre la filosofía de la naturaleza y ésta sobre la lógica, es decir sobre la metafísica. A su vez, la psicología no está en la antesala de la metafísica, sino de la filosofía del espíritu objetivo, es decir de la Filosofía del Derecho, y de la Cultura en general.

Pues bien, al seguir este proceder, Hegel parece ser más bien aristotélico que kantiano. Ya en el comienzo de la parte expositiva del De anima, el libro II, recurre a las doctrinas que estableció en la Metafísica, sobre el hilemorfismo, el acto y la potencia, y los sentidos del acto. Es con esta base o fundamento 
metafísico con lo que puede tratar de los fenómenos que se dan en lo vivo. De modo que Aristóteles entiende su quehacer como un remitir a su fundamento metafísico los fenómenos y hechos que observa y determina.

Además, aunque para Aristóteles la psicología forma parte de la física, porque el estudio de los seres vivos tiene como presupuesto que estos son realidades naturales, no obstante, el insiste en que el analogado principal del ser natural es el organismo vivo. ${ }^{11} \mathrm{Y}$ por ello tendría sentido parafrasear a Aristóteles desde Hegel, afirmando que los organismos vivientes vienen a ser algo así como la verdad de los seres físicos.

Por su parte, la panorámica general e introductoria a los seres vivos que es el De anima es completada con la reflexión filosófica sobre la psico-fisiología realizada en los diferentes tratados de los Parva Naturalia y en las grandes obras sobre zoología que son Las partes y la generación de los animales, ${ }^{12} \mathrm{de}$ forma que lo que es presentado en el De anima aporéticamente, es resuelto en tratados ulteriores merced a lo que podríamos denominar una filosofía de la biología. Es decir, Aristóteles no admitiría que el tratamiento empírico no tuviese nada que decir al especulativo. Pero sobre todo afirmaría, con Aristóteles que el fundamento de lo empírico se encuentra en lo metafísico.

No obstante, no hay que despreciar el hecho de que para Aristóteles los libros acerca del alma se insertan en un conjunto de reflexiones sobre la naturaleza. Para Hegel en cambio, la misma denominación «Filosofía del espíritu» indica a las claras que el lugar sistemático para tratar de la antropología y la psicología, no es la naturaleza, sino separado y elevado sobre ella. Hegel es tan moderno como Descartes o Kant al considerar el alma como algo humano, y no meramente natural, o como propio de los seres vivientes. Pero se distingue de ellos al considerar la relación que tiene lo anímico con lo natural y, su emerger desde lo natural. Por ello, lo psíquico y el espíritu no son tematizados como lo completa y totalmente separado de lo natural. La antropología tiene como tema este emerger del espíritu desde su hundimiento en la naturaleza. Y como veremos, esto tiene una importancia decisiva al tratar de la autoconciencia y de su relación con la sensibilidad.

Para Hegel el concepto es el logos o unidad de todo lo que acontece, ya en el cosmos ya en la historia. Y esto es particularmente verdadero en el caso del espíritu subjetivo, que se apropia y configura la realidad empírica, exterior, que en sus manos viene a ser como plástica y maleable. Es decir, la realidad del espíritu no cae aparte de la de la naturaleza, sino en y dentro de la naturaleza, como recientemente ha puesto de relieve Angelica Nuzzo. También Ferrarin

11 De anima II, 1.

12 Cfr.: Kahn, Ch. H., «Sensation and Consciousness in Aristotle’s Psychology" en Archiv für Geschichte der Philosophie, 48/1966, p. 47 y ss. 
señala que «lo que Hegel encuentra en el De anima no es un logro menor ( $V G P h$ 199-221): el alma como vida, Idea, una actividad y un auto-desarrollo en y a través de su relación con lo otro»». ${ }^{13}$

\section{El eSpíritu (COMO GeIST, E INCLUSO COMO PSIQUismo) ES EN CIERTA MANERA TODAS LAS COSAS}

Para Hegel, llevar el concepto al conocimiento del espíritu es algo más hacedero que hacerlo con la naturaleza. En esto sigue a Descartes, quien afirmó decididamente la mayor evidencia y certeza que corresponde al yo respecto del mundo natural y las otras mentes. La naturaleza es exterioridad pura, tanto que en ella el concepto siempre es exterior a su realidad. Las ciencias empíricas atienden a los fenómenos, a aquello que se manifiesta. La filosofía de la naturaleza antigua y moderna remitía esos fenómenos a su fundamento, a su

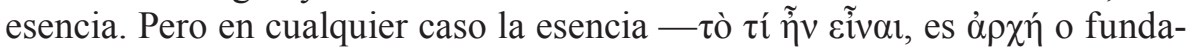
mento de las entidades vivas, fundamento al que Aristóteles llama $\psi v \chi \eta ́-$ - y el fenómeno se disciernen en el cosmos. Y así es tratado por las ciencias bien empíricas bien filosóficas que se ocupan de ello.

Pero el espíritu es subjetividad, y por ello es precisamente la interioridad en la que lo que acontece es acogido y tenido en presente. Con la vida orgánica se iniciaba una superación de la exterioridad física. En la vida lo exterior es asimilado, se hace interior, y por eso la vida es reflexión. Y esto implica para Hegel una supresión de la causalidad exterior y mecánica. Lo exterior puede afectar al ser vivo, en tanto que vivo, tan sólo en la medida en que éste transforma y aprovecha para sí el influjo recibido del exterior. ${ }^{14}$ Así es como Hegel reformula el tema clásico de la inmanencia vital.

Pero la subjetividad que compete al espíritu es tal que su interioridad puede alojar cabe sí todo - lo que no es espíritu, y lo espiritual—: también todo lo que era irreductiblemente plural, heterogéneo y externo. Eso es obtener el concepto de un acontecer o de todo acontecer, sea este acontecer natural, sea el inaugurado por el juego de las libertades: es decir, histórico. Por eso «el espíritu no está meramente más allá de la yuxtaposición y exterioridad naturales; lo que falta a la naturaleza es la dialéctica de lo interno y lo externo. El espíritu es la interiorización de la exterioridad y de toda otredad, así como la exteriorización de la interioridad».. ${ }^{15} \mathrm{Y}$ en este sentido Hegel concordaría con Aristóteles en que el alma es en cierto modo — esto es: espiritualmente — todas las cosas, al interiorizarlas.

13 Ferrarin, A., Hegel and Aristotle, Cambridge University Press, Cambridge MA, p. 241.

14 Hegel, WdL II: 227-29. Citado por Ferrarin, p. 13.

15 Ibid., p. 237. 
Y esto, para Hegel se produce ya desde las primeras manifestaciones del espíritu. No hace falta esperar al intelecto. El psiquismo es ya un reflejo de todo. Por esta razón, Hegel afirma que cada psique humana refleja todo el universo, ya de modo sustancial. Y si esto acontece ya sustancialmente, mucho más en las primeras apariciones del ser para sí — Fürsichsein-, en el despertar y la sensación. Es espíritu es todas las cosas, también sintiéndolas. Veámoslo.

Como el espíritu es vida, la interiorización no es un mero reflejo de lo impreso a él desde el exterior. El espíritu no está sujeto a una causalidad mecánica que actuase sobre él, sino que aquello que puede ser y existir en el espíritu es aquello que el espíritu pone cabe sí. El espíritu es activo, nunca meramente pasivo, sino activo incluso en su pasividad y receptividad. Y esto implica que en el espíritu la esencia no se distingue de su aparecer, de su manifestación. El espíritu es como aparece y aparece como es. Pero esto sólo puede ser así

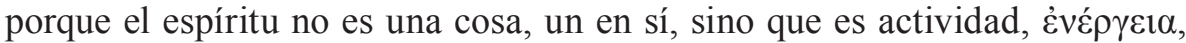
Tätigkeit, Aktuosität. Es su propia actividad la que genera el concepto, la que se hace todas las cosas.

Y si puede ser todas las cosas, también puede hacerse ella misma, también le cabe llevar a concepto su propia realidad.

El fin esencial de una filosofía del espíritu solamente puede ser el de llevar de nuevo el concepto al conocimiento del espíritu y de continuar así el sentido de aquellos libros aristotélicos. ${ }^{16}$

El concepto es el modo de ser en el que lo acontecido no está según su modo propio, sino como posesión ideal en quien lo sabe. Lo natural no está así como lo exterior y otro, sino según el modo del que lo sabe. Por ello el espíritu es negación. Niega lo exterior como modo de ser, lo cambia de signo, o lo transforma en su modo de ser. De en sí, lo dado, lo inmediato, lo que simplemente está ahí, pasa a ser para el espíritu, y por lo tanto mediado por su actividad, e idealizado en su intimidad.

Pero hay una diferencia tremenda entre el ser vivo y el espiritual. El espíritu muta todo en existencia ideal, también su propia vida orgánica. En cambio, el animal no es capaz de la actividad idealizante. Lo más que consigue el animal es vivir el género en la experiencia de ir más allá de su individualidad, e incluso arriesgarla, en la experiencia de la pulsión sexual. En el impulso reproductivo, el animal siente su unidad con lo genérico, su identidad con otro individuo del mismo género. Pero el animal no logra conceptualizar esta unidad. No logra alcanzar el concepto universal de que él es un animal de tal especie. En cambio, al espíritu le compete idealizar cualquier cosa, también su propia vida e incluso sus condiciones biológicas. Por ello su relación sexual es diferente a la que se

16 Hegel, Enz., § 378 . 
da en el reino animal. Un individuo se relaciona con el otro no como macho o hembra, sino como hombre o mujer, su pulsión biológica recibe nuevos significados, etcétera. La vida ya no es regida desde el género, desde lo exterior al individuo, sino desde la propia subjetividad. La vida espiritual está principiada por el sujeto y desde su conocimiento. También en lo que tiene de orgánico: la nutrición humana ha dado lugar a la gastronomía, su supervivencia física a la arquitectura, al diseño y la moda, etc.

Esto tiene suma importancia para el tema de la percepción humana. En efecto, ricas instituciones culturales y prácticas humanas como la destilería de bebidas, la floristería, la gastronomía, etcétera, tienen en su base la armonía o disarmonía de una realidad con el psiquismo y la subjetividad. Por lo tanto, presuponen el fenómeno del encontrar-se del alma consigo. La manifestación de la subjetividad en el juicio sensible. Esto o aquello gusta, o disgusta, cae bien, entusiasma o entristece, etc. Estos fenómenos no sólo están en la base de las prácticas antes mencionadas. También fundamentan el modo primario y originario de vivir todas las realidades del cosmos y las otras subjetividades. ${ }^{17}$

$\mathrm{Y}$ es que la idealización de la vida tiene lugar ya mucho antes de la actividad autoconsciente. El espíritu se despierta emergiendo de su hundimiento en lo natural. Y ya en los primeros estadios el espíritu aparece como es, como libre, incluso respecto de las condiciones naturales que lo encadenarían como ser vivo: el medio ambiente, la condición sexuada, y evolutiva del psiquismo humano, el alterarse del sueño y la vigilia, el propio temperamento, las capacidades senso-motoras y afectivas. Todas estas condiciones del vivir humano, al ser idealizadas quedan canceladas como condiciones genéricas y pueden llegar a ser expresiones del individuo. Así lo otro del espíritu, lo encontrado inmediatamente, pasa a ser expresión, algo puesto por él, y que le permite relacionarse consigo, es decir manifestación del espíritu y no de la naturaleza. Lo biológico, al ser apropiado por el espíritu, deviene también instrumento suyo.

Pero volvamos a Aristóteles y veamos cómo tematiza el primer encuentro vital del alma consigo misma.

\section{LA AUTOCONCIENCIA SENSIBLE EN ARISTÓTELES}

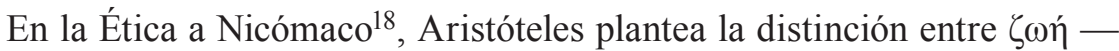
vida orgánica - y ßíos — vida espiritual—. La vida orgánica está sujeta a los ciclos biológicos de los que depende. Pero el ßíos es la vida que sabe de sí, y que precisamente por ella es capaz de enfrentarse a la muerte biológica, es

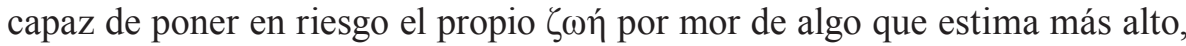

17 Cf:: Choza, J., Manual de antropología filosófica, Thémata, Sevilla, 2016 (2ª edición), p. 233

18 Aristóteles, Ética a Nicómaco, X 7, 1177b 33 
y por lo tanto de disponer de él, precisamente porque sabe de sí, porque es au-

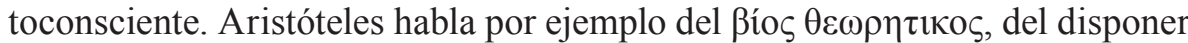
de la vida en orden a conocer: la vida contemplativa, para la que es preciso un control muy determinado de los apetitos y las pasiones, como escribirá siglos

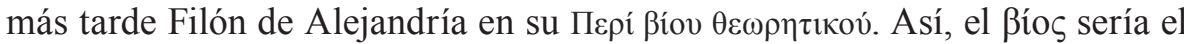
tipo de vida que correspondería al espíritu, según Hegel.

Pero la relación entre ßíos y $\zeta \omega \eta ́$ no es entre dos realidades independientes, entre un sujeto autoconsciente y una cosa extensa, un complejo mecanismo físico-químico-biológico, al modo cartesiano. Ni así lo piensa Aristóteles, ni así lo hace Hegel. Más aún, aquí está la razón por la que Hegel encuentra que Aristóteles «concibió el alma especulativamente». ${ }^{19}$

Para Hegel, Aristóteles había acertado al incluir las formas de vida inferiores en las superiores, como el triángulo es una figura que existe potencialmente en las demás figuras geométricas de orden superior. No es que el cuadrado se genere a partir de dos triángulos, sino que un cuadrado puede analizarse en triángulos, que están en él, sin que lo generen. Del mismo modo, el alma sensitiva no es independiente de la vegetativa, ni estas dos - $\omega \hat{\eta}$ - son independientes de la intelectiva - $\beta$ ío $\varsigma$ - No son separables porque son momentos de un único sujeto. Del mismo modo las facultades del sujeto no pueden pensarse como independientes, autosuficientes y separables.

Las funciones vegetativas - la nutrición y reproducción - en el animal son el objeto de los procesos sensitivos y de su conducta impulsiva. Por eso en el De anima 413b Aristóteles dirá que «el animal lo es primariamente en virtud de la sensación» queriendo decir que vive como animal porque siente, y no que el conocer sea un tipo de vida separable de los procesos fisiológicos. Del mismo modo, desde el intelecto cabe asumir y regular las actividades vegetativas y sensitivas, convirtiendo los modos en que el ser humano atiende a sus necesidades biológicas en ricas manifestaciones de su espiritualidad. Ahí, en las funciones vegetativas y sensitivas cabe detectar el dominio del intelecto. Es por esto por lo que Hegel señalará que

En el ser humano, no se tiene tan sólo la presencia de una naturaleza vegetativa, puesto que él es también, y con el mismo alcance, sentiente y pensante; en el ser humano estas son tan sólo tres formas que, en él, son una y la misma. ${ }^{20}$

En la Ética a Nicómaco Aristóteles se había planteado el tema del acto cognoscitivo con que se conoce el propio conocer. Se trata de un texto muy polémico, que fue sometido por Bywater a una enmienda en 1890, y que por

19 Hegel, G.W.F., Lecciones sobre filosofia del espiritu subjetivo. Vol. I. Introducciones, Thémata, Sevilla, 2015, p. 37.

20 Nota del manuscrito de Kehler citado por Petry, vol. I., p. 10. 
lo tanto es diferente al que conocieron neoplatónicos, medievales o el mismo Hegel. El texto dice así:

El hombre que ve percibe que está viendo, quien oye (percibe) que está oyendo, el que camina (percibe) que camina, y de modo similar para otras actividades hay algo que percibe que estamos actuando, de modo que si estamos sintiendo (percibe) que estamos sintiendo, y si estamos pensando (percibe) que estamos pensando. Pero (percibir) que estamos sintiendo o pensando es (percibir) que existimos - pues nuestra vida y ser (como humanos) ha sido definida como sintientes o pensantes; y percibir que se está vivo es algo intrínsecamente agradable. ${ }^{21}$

El interés de Aristóteles no está aquí en las diferentes operaciones de la sensibilidad externa, ya sea el ver, el oír o la sensibilidad cinestésica. Más bien su interés estriba en cualquier tipo de percepción que se sitúe más allá de estas operaciones especializadas y distintas con que nos referimos a diferentes aspectos de la realidad física. Aristóteles se pregunta por la percepción del sentir en general, del pensar o del vivir. Y por eso, se está planteando el tema de la conciencia, ya sea sensible, intelectual o vital.

Pero nótese que, en este lugar, al tratar de la percepción de actos como el caminar, el oír - o cualquier otra percepción-, el entender y el propio existir, Aristóteles está preguntándose por cómo se perciben los diferentes actos vitales. Si entender es un acto vital, entonces para él no tiene sentido distinguir entre actos del psiquismo y actos del intelecto. Unos y otros son actos vitales. Y por eso, Aristóteles inquiere por el modo en que la vida encuentra a la vida, es decir, por el modo en que la vida se encuentra consigo.

Este tema también lo plantea en una famosa aporía del capítulo 2 del libro III del De anima. ${ }^{22}$

Dado que percibimos que vemos y oímos, el acto de ver habrá de percibirse forzosamente o con la vista o con algún otro sentido. Ahora bien, en este último supuesto el mismo sentido captaría la vista y el color, objeto de ésta. Luego habrá dos sentidos que capten el mismo objeto a no ser que el mismo sentido se capte a sí mismo. Pero es que, además, si fuera otro el sentido encargado de captar la vista o bien habrá una serie infinita o bien habrá, en último término, algún sentido que se capte a sí mismo. Establezcamos esto, pues, respecto del primero de la serie.

La aporía es clara: o hay dos facultades que perciben lo mismo, lo cual parece absurdo, pues habría una reduplicación de actos perceptivos, lo que

21 Ibid., 1170a 29-b1.

22 Cfr.: Osborne, C., «Aristotle, De Anima 3.2: How do we perceive that we see and hear?» en Classical Quaterly 33/1983, pp. 401-411. 
pone contra las cuerdas cualquier teoría que intente explicar con un mínimo de economía de principios, o hay un proceso al infinito: para percibir que se ve se debería admitir otro sentido que percibiera que se percibe, lo que exigiría un nuevo acto que percibiera esta otra percepción... Así pues o tenemos el absurdo de dos facultades perciben lo mismo o el regreso al infinito de una actividad que percibe el objeto y otra distinta percibe el percibir.

Parece como si Aristóteles quisiese presentar y subrayar las dificultades a las que se enfrenta la conciencia sensible. Conciencia que postula se daría en el punto cero de una serie de actos cognoscitivos sensibles. En los Parva Naturalia resolverá esta aporía al hablar de este punto cero como raíz o centro de la sensibilidad externa. Es un punto cero porque es anterior a la división a los diferentes sentidos, de modo que es común a ellos, estando en su centro y raíz. Así en el De Sensu señala que

Hay que suponer que la facultad que percibe todos (los objetos y cualidades sensibles) es una en número y la misma, aunque su modo de ser es diferente, ya en género (respecto de los diferentes sentidos), ya en especie (lo dado a un sentido dado). ${ }^{23}$

Así es como termina el tratado Acerca de la sensación y de lo sensible, distinguiendo la facultad sensitiva de sus especializaciones. El sentido común

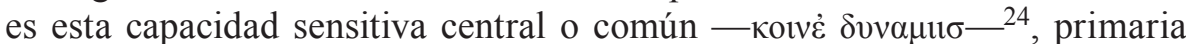

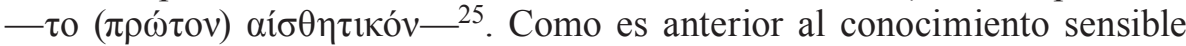
especializado, lo hace posible, y por ello Aristóteles lo llama el principio de la

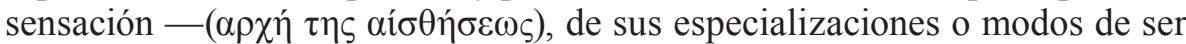
como captación del color, del sonido, del movimiento, de las acciones, de los estados afectivos, de la vida o quizá también del pensamiento.

Victor Caston ${ }^{26}$ y Juha Sihvola ${ }^{27}$ se oponen a esta lectura sistemática y expositiva de la doctrina aristotélica sobre la sensación, y mantienen el carácter reflexivo del acto sensitivo. Según ellos, «este acto incluye dos aspectos (i) el ver un objeto visible, y (ii) la conciencia reflexiva del mismo acto. Esta conciencia es por una parte intrínseca, es decir, incluida en el acto perceptivo original y por otra intencional y relacional al estar dirigida reflexivamente al acto

23 De sensu 449a 15-20.

24 De somno, 2, 455a15-22.

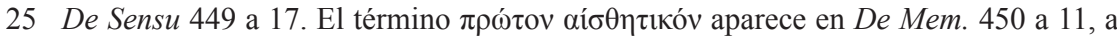
14, De Somno 454a 23

26 Caston, V., «Aristotle on consciousness» en Mind 111/2002, pp. 751-815.

27 Sihvola, J., «The Problem of Consciousness in Aristotle's Psychology» en Heinämaa, S., Lähteenmäki, V., Remes, P., (eds.), Consciousness: From Perception to Reflection in the History of Philosophy, Springer, Dordrecht, 2007, 
perceptivo mismo». ${ }^{28}$ Según ellos habría dos tipos diferentes de percepción: la una directa, la otra reflexiva, pero un único caso de actividad. O dicho de otro modo, en un único estado mental se darían las dos percepciones o intenciones: una directa y otra refleja.

Según Sihvola «la idea de cierto tipo de conciencia reflexiva intrínseca a todos los actos perceptivos puede ser generalizada a las otras formas de actos mentales, incluyendo el pensar y las emociones». ${ }^{29}$ Pero me parece que introducir esta dimensión reflexiva en la sensibilidad es más hegeliano que aristotélico. $\mathrm{O}$ al menos es congruente con el tratamiento de la sensibilidad en la filosofía del espíritu subjetivo, y quizá no lo sea tanto con la mente de Aristóteles.

IV. HEGEL Y LAS FORMAS ANTROPOLÓGICAS DE ENCONTRARSE DEL ESPÍRITU A Sí MISMO

Que en el acto haya dos tipos diferentes de actividad implica que la sensibilidad no es mera pasividad receptiva de contenido. Es decir, que el tratamiento lockeano o kantiano de la sensibilidad es inapropiado. Es el mismo sentido el que detecta la praxis vital o cognoscitiva ejercida. Por ello, sostiene Ferrarin que los sentidos «no son el material pasivo, recalcitrante e instrumento de una razón recelosa que realiza experimentos y examina los casos sensibles a la luz de ellos. Los sentidos nos proporcionan una percepción activa e inteligente, y no meramente los supuestos datos sensibles o el material ciego y heterogéneo necesitado de la unificación intelectual. Los sentidos mismos son autoconscientes, en tanto que detectamos nuestra sensación a través de las cosas sensibles que discriminamos (De an. III 2, 426b 10-11, 1, 425b 12 ss.)». ${ }^{30}$

Es así como según Hegel el alma también se encuentra a sí misma. Se encuentra como acto, se diferencia del contenido porque este ha sido recibido pasivamente. Se encuentra pues como movimiento vital, como negatividad de lo inmediato, como individualidad. Y aquí aparece una nueva diferencia con el criticismo kantiano. La sensibilidad no es vista como una facultad del alma, sino como la propia alma que siente, como su individualidad.

En esta alma sentiente - empfindende Seele-, Hegel distingue dos tipos de determinaciones: las que el alma encuentra como procedentes de los sentidos externos y las que proceden del interior del alma, como movimientos - emociones - que se han producido en ella — pasiones - , y que afectan su modo de vivir - afectos- En unas determinaciones y otras el alma teje sordamente, es activa al recibir. Este tejer es un interiorizar en el caso de las afecciones externas, y un encarnar o somatizar, en el caso de las afecciones externas. Así 
es como se posee idealizadamente las cualidades físicas sentidas, y como se idealizan las sensaciones de nuestro cuerpo, que idealizadas aparecen como sentimientos.

\section{IV.1. EL DESPERTAR COMO ENCONTRARSE (SICH-FINDEN)}

El alma ya se encuentra consigo antes de sentir. En la Antropología Hegel estudia el despertar como una forma de encontrarse. En rigor esta es la protoforma del ser para sí — Fürsichsein_- El primer modo en que el psiquismo se encuentra consigo y es para sí, la primera forma en que la subjetividad psíquica aparece para sí misma. No se trata de que el psiquismo tenga estas cualidades y se encuentre en este o aquel estado. Esas cualidades y estados son en el alma - an ihr-, la cualifican y la alteran. Y por ello tienen vienen a ser los accidentes de nuestra sustancialidad. Pero al despertar el alma se encuentra a sí - Sichfinden - de un modo que no tiene por que ser el de la conciencia racional y reflexiva. Se trata de un encontrarse pre-racional en el que el alma vive o experiencias las cualidades y alteraciones existentes - seiend - en ella.

Así para Hegel la intimidad subjetiva aparece en los procesos psíquicos de interiorización. En la intimidad anímica existen, en forma idealizada, todas las determinaciones naturales, y las múltiples y misteriosas relaciones que el sordo tejer del espíritu ha realizado con todo ese material. Todo ello es en el hondo abismo nocturno ${ }^{31}$ del alma. Todo ello está en ella -an ihr-. En un principio de forma existente. Pero todo ello puede ser vivido por el alma. Y eso en primera instancia significa ser sentido por ella.

Hegel trata de la sensación como la mediación que supera la distinción entre el sueño y la vigilia, entre el hundirse pasivo en la propia sustancialidad y el despertar a la actividad. En efecto, en la sensación hay pasividad. Pero ésta no consiste en un mero ser afectado, sino que la actividad interiorizante e inconsciente del espíritu sobre su propia capacidad sensitiva, a la que transforma merced a su propia actividad, es decir, la desarrolla. Por eso, la comprensión hegeliana de la sensibilidad se aleja tanto de la mera receptividad kantiana como de la dación sensible empirista, acercándose en cambio a una lúcida comprensión del conocimiento sensible en Aristóteles. ${ }^{32}$

31 En las dos primeras ediciones de la Enciclopedia, Hegel prosigue estas metáforas de lo oscuro, la profundidad, el pozo, encabezando esta sección como «el alma que sueña - die traümende Seele - en la tercera edición el título y tema de la misma es, en cambio, el alma que siente - die fühlende Seele-.

32 Cfr.: Ferrarín, A., Hegel and Aristotle, Cambridge University Press, Cambridge MA, 2001, pp. 268 y ss. 
IV.2. LA SENSACIÓN COMO ENCONTRARSE PRE-CONSCIENTE Y CORPORAL CON LA PROPIA INTERIORIDAD: LA CONCIENCIA VITAL EN HEGEL

El tratamiento hegeliano de la sensación en las lecciones de antropología difiere del que llevó a cabo en la Fenomenología del espíritu. Allí se preguntaba por la experiencia sensible, su alcance y sus límites. Aquí, en cambio, el sentir es investigado en cuanto que estado natural, que compartimos con el resto de los animales, aunque de un modo que nos separa profundamente de ellos.

Esto es importante, porque en la sensación, tal y como la aborda Hegel en la antropología, no cabe hacer una distinción entre sujeto y objeto. En los niveles de la fenomenología y la psicología la actividad de la sensibilidad es diversa. Pero hay una actividad sensible pre-consciente que Hegel detecta. Podríamos calificar estrictamente el nivel de la antropología como «subconsciente». Aún no ha emergido la conciencia, y estamos sumidos inconscientemente en nuestra corporalidad orgánica, de la que sin embargo estamos separados originariamente.

Por eso, las sensaciones y los sentimientos, en nuestro estado de hundimiento en la corporalidad, no se corresponden con objetos externos. En este nivel Hegel estudia el sentir, sin diferenciar exhaustivamente entre sensación y sentimiento, dirigiendo la atención hacia la interioridad, al espacio ideal - un pozo carente de determinaciones, bestimmungsloser Schacht_-33 en el que existe idealmente lo que se siente. En este nivel sustancial, Hegel advierte lúcidamente una serie de actividades espirituales sumamente importantes.

$\mathrm{Ni}$ en la sensibilidad animal, ni en la actividad sensible pre-consciente humana, se da separación entre el perceptor y lo percibido, entre el individuo particular que siente y el contenido sentido. Esta separación es propia de la autoconciencia. Al sentir no es posible esta distinción, esta «oposición de algo objetivo frente al sujeto». ${ }^{34}$ La determinidad sentida no está separada y frente al sujeto, sino que afecta siempre inmediatamente al sujeto. Es una afección suya, «pertenece a la propiedad natural y más particular de éste [del sujeto]». ${ }^{35}$ Uno está afectado, se encuentra determinado. El sujeto al sentir no puede separarse en modo alguno, ni siquiera mentalmente, de la sensación. Es decir, no cabe ejercicio alguno de reflexión en el que el sujeto pudiese reparar por un lado en sí y por otro en lo que siente, sino que sentir es un encontrarse inmediatamente afectado. Sentir es una actividad pre-reflexiva porque es imposible separar la actividad «yo siento» del «qué» que se siente.

Esto es perfectamente kantiano. Pero Hegel añade que la mera afección no basta para definir la sensación. Y en esto, Hegel se muestra aristotélico: actio in 
passio. No admite la oposición racionalista y empirista entre acción y pasión. Para que se dé afección sensible ha de haber una actividad espiritual. La recepción es activa. Y esto diferencia la afección sensible de la física. La sensación no es una mera alteración. Y por eso Hegel sitúa su lugar sistemático fuera de las alteraciones naturales. No porque nuestros órganos sean impresionados, sentimos; aunque éste sí sea un requisito del sentir. Es precisa una actividad espiritual que recibe en la intimidad subjetiva lo sentido. Y esto porque lo que hay en el espíritu no es separable nunca de la actividad del espíritu. Éste ha de ponerlo dentro de sí, ha de tomar posesión - Besitz - de lo que lo determina y darle un tipo de existencia que es la del espíritu, idealizarlo. Estos contenidos, entonces, pertenecen tan íntimamente al sentir que son suyos, los asimila a sí, a la particularidad del viviente, y no a un yo que pudiera contemplarlo a distancia.

La gravedad, las diferencias térmicas, químicas, la luz, las ondas sonoras, etcétera, son sentidas y vividas por un cuerpo natural. Este cuerpo tiene en cada momento un determinado peso, una determinada temperatura, etc. Esta cualificación es exterior, un mero ser afectado. En cambio, sentirlas implica, pues, en primer lugar, una interiorización de lo que cualifica exteriormente. Es decir, una negación de la exterioridad. Por eso, sentir no es una mera cuestión de ser afectado. Sentir, ante todo, es una cuestión de asimilación o interiorización de lo externo a la propia idealidad. Así es como lo entiende también Aristóteles, quien habla de la actualización de la sensibilidad como de un cambio asimilativo — metabolên - que permite, a su vez, una mejor disposición de la capacidad sensitiva. ${ }^{36}$

Tal cambio es un tornar lo existente - das Seiende - en una determinación ideal; lo exterior sucesivo y disperso en el espacio, en lo que existe idealmente en la propia interioridad. Se trata de una negación de lo exterior y meramente existente que sin embargo lo conserva idealmente recogiéndolo y depositándolo en el nocturno pozo de la interioridad. Esta interiorización inconsciente en la que lo distendido espacio-temporalmente es preservado de su transitoriedad, es propiamente el espíritu. Su actividad es pues la de una memoria - erinnerung - que salva a lo existente de su fugacidad porque lo interioriza - porque lo incorpora - er-en la interioridad - inner-. Y sentir es justamente innewerden, percatarse interiormente.

Y esto implica, no sólo un cambio en la capacidad sensitiva, sino cierta transformación de lo exterior. Transformación en la que lo sentido adquiere relaciones con lo ya depositado en nuestra interioridad que de suyo no tenía. Por eso, Hegel dirá que sentir, es ya desde su mismo inicio una actividad. Esta actividad, en su grado más bajo, es un «sordo tejer» — dumpfen Webens ${ }^{37}$ -

36 Aristóteles, De anima, II 5, 417b 16.

37 Enz., C $§ 400$. 
Este tejer deriva etimológicamente de wimmeln, un moverse rápidamente de aquí para allá de forma zigzagueante, serpenteando. Entretejer, entrelazar es esa primaria actividad del espíritu, en la que inconscientemente lo exterior va siendo entrelazado con lo que hay ya en el sujeto, y por lo tanto puesto en conexiones del todo contingentes, singularmente nuestras.

Esta contingencia del sordo tejer y asociar se observa nítidamente en las ensoñaciones. En ellas se observa que el sordo tejer del espíritu no necesita de estímulo exterior alguno, de ser afectado o de lo dado, sino de lo que ya está en posesión del espíritu. Una posesión que es ideal, y que el espíritu activa desde sí mismo.

Pero sí el espíritu siempre teje sordamente, y eso es propiamente el sentir, entonces cada nueva afección que llega al alma incide sobre la sensibilidad, modifica el modo en que esta entrelaza y entreteje, al menos en la forma de contar con más elementos a tejer.

Otra actividad que el sí mismo pone al sentir es interiorizar tanto lo externo que lo hace asimilable a su propia constitución orgánica: lo somatiza, lo siente corporalmente. Más aún, en cuanto que la interioridad ha sido modificada, no sólo se ha modificado el psiquismo, sino que este es sentido somáticamente, se encarna. Esta es la primera toma de posesión de uno, un apropiarse corporalmente de la propia interioridad.

Así el alma que siente encuentra también sus afecciones internas, y las encuentra en la forma de existencias inmediatamente presentes - Dasein-. Las encuentra encarnadas en el organismo. O mejor aún, la encarnación es la forma encontrada por la emoción o la pasión. Estos sentimientos han encontrado su forma en tanto que se corporalizan. Así, el alma encuentra la ansiedad o la preocupación somatizada en el sistema digestivo o en la transpiración. La ira en el sistema respiratorio y el circulatorio, etc. Hegel insta a realizar una fisiología psíquica. Una fisiología que no sólo tenga que ver con el estudio de lo funcional en el organismo humano, sino con la expresión psíquica, con la interioridad que se significa fisiológicamente. También aquí Hegel se aleja de la consideración meramente mecánica del empirismo.

JuAn J. PADIAL es profesor titular de filosofía en la Universidad de Málaga.

Lineas de investigación:

Antropología filosófica, filosofía de la cultura, idealismo alemán. 
Últimas publicaciones:

«La mónada como simple vida ideal del alma según Hegel» en Sánchez Rodríguez, M., y Escribano Cabeza, M., Leibniz en diálogo, Thémata, Sevilla, 2017.

«La psicología de la obra de arte según Hegel» en Paredes, Mª C., Bonete, E., Filosofía, arte, mistica, Ediciones Universidad de Salamanca, Salamanca, 2017.

Email:jjpadial@uma.es 
